Research

\title{
Phenotypical and functional characterization of alveolar macrophage subpopulations in the lungs of $\mathrm{NO}_{2}$-exposed rats Holger Garn*1, Anette Siese ${ }^{2}$, Sabine Stumpf ${ }^{2}$, Anka Wensing1 ${ }^{1}$ Harald Renz ${ }^{1}$ and Diethard Gemsa ${ }^{2}$
}

\begin{abstract}
Address: ${ }^{1}$ Department of Clinical Chemistry and Molecular Diagnostics, Philipps University of Marburg, Biomedical Research Center, HansMeerwein-Str., 35043 Marburg, Germany and 2Institute of Immunology, Philipps University of Marburg, Robert-Koch-Str. 17, 35037 Marburg, Germany

Email: Holger Garn* - garn@staff.uni-marburg.de; Anette Siese - asiese@web.de; Sabine Stumpf - sabine@stumpf.web.de; Anka Wensing - anka.wensing@med.uni-marburg.de; Harald Renz - renzh@med.uni-marburg.de; Diethard Gemsa - gemsa@med.unimarburg.de

* Corresponding author
\end{abstract}

Published: 06 January 2006

Respiratory Research 2006, 7:4 doi:10.1186/1465-9921-7-4
Received: 15 August 2005

Accepted: 06 January 2006

This article is available from: http://respiratory-research.com/content/7///4

(c) 2006 Garn et al; licensee BioMed Central Ltd.

This is an Open Access article distributed under the terms of the Creative Commons Attribution License (http://creativecommons.org/licenses/by/2.0), which permits unrestricted use, distribution, and reproduction in any medium, provided the original work is properly cited.

\begin{abstract}
Background: Alveolar macrophages (AM) are known to play an important role in the regulation of inflammatory reactions in the lung, e.g. during the development of chronic lung diseases. Exposure of rats to $\mathrm{NO}_{2}$ has recently been shown to induce a shift in the activation type of AM that is characterized by reduced TNF- $\alpha$ and increased IL-10 production. So far it is unclear, whether a functional shift in the already present AM population or the occurrence of a new, phenotypically different AM population is responsible for these observations.

Methods: AM from rat and mice were analyzed by flow cytometry for surface marker expression and in vivo staining with $\mathrm{PKH} 26$ was applied to characterize newly recruited macrophages. Following magnetic bead separation, AM subpopulations were further analyzed for cytokine, inducible NO synthase (iNOS) and matrix metalloproteinase (MMP) mRNA expression using quantitative RT-PCR. Following in vitro stimulation, cytokines were quantitated in the culture supernatants by ELISA.

Results: In untreated rats the majority of AM showed a low expression of the surface antigen ED7 (CDIIb) and a high ED9 (CDI72) expression (ED7-/EDghigh). In contrast, $\mathrm{NO}_{2}$ exposure induced the occurrence of a subpopulation characterized by the marker combination ED7+/ED9low. Comparable changes were observed in mice and by in vivo labeling of resident AM using the dye PKH26 we could demonstrate that CDIIb positive cells mainly comprise newly recruited AM. Subsequent functional analyses of separated AM subpopulations of the rat revealed that ED7 ${ }^{+}$cells showed an increased expression and production of the antiinflammatory cytokine IL-10 whereas TNF- $\alpha$ production was lower compared to ED7- AM. However, iNOS and IL-12 expression were also increased in the ED7 ${ }^{+}$ subpopulation. In addition, these cells showed a significantly higher mRNA expression for the matrix metalloproteinases MMP-7, $-8,-9$, and -12 .
\end{abstract}

Conclusion: $\mathrm{NO}_{2}$ exposure induces the infiltration of an $\mathrm{AM}$ subpopulation that, on the one hand may exert antiinflammatory functions by the production of high amounts of IL-10 but on the other hand may contribute to the pathology of $\mathrm{NO}_{2}$-induced lung damage by selective expression of certain matrix metalloproteinases. 


\section{Background}

The special situation in the lung, that exposes an epithelial surface of about $200 \mathrm{~m}^{2}$ to the environment, requires effective defense mechanisms to safe the organism from the entry of foreign substances including pathogenic microorganisms. Indeed, the mammalian lung is equipped with a variety of defense systems that include mechanical and chemical barriers (e.g. cough reflex, mucociliary escalator, mucus, surfactant, lysozyme, defensins) as well as mechanisms of the innate and adaptive immunity (e.g. macrophages, dendritic cells, secretory IgA, bronchus-associated lymphatic tissue) [1,2]. Invading foreign materials may pass into different parts of the airways or even the lung parenchyma due to different physical and chemical properties. Therfore, certain components of the pulmonary defense system are localized at different quantities in the several parts of the lung and within the distal airways and the lung parenchyma macrophages comprise the most important cellular structures of this system [3].

Even though macrophages may occur in different localizations in the lung, alveolar macrophages (AM) are the best characterized pulmonary macrophage population $[4,5]$. Their special localization outside the epithelial barrier requires a specific adaptation to this environment and, indeed, AM differ in certain phenotypical and functional parameters not only from macrophages from other organs $[6,7]$ but also from interstitial pulmonary macrophages $[4,8]$. On the one hand they are characterized by a higher capacity to phagocytose foreign material, increased production of reactive oxygen and nitrogen species and of the pleiotropic cytokine TNF- $\alpha$. In contrast, they release reduced amounts of the proinflammatory cytokines IL-1 $\beta$ and IL- 6 and show only a weak surface expression of MHC-class-II molecules and costimulatory molecules such as CD80 and CD86 [9]. These properties imply, that $\mathrm{AM}$ are very effective in the defense of microbial invaders, however, do not necessarily induce an inflammatory reaction or initiate an adaptive immune response [10]. With this respect, AM fulfill rather "classical" macrophage functions, i.e. direct defense of microorganisms and show only poor immunostimulating properties. In fact, they may even induce reversible anergy in T lymphocytes [11].

The situation may change significantly when an inflammatory reaction is induced. For example, AM with a rather monocytic phenotype appear following intratracheal administration of LPS or the CXC chemokine MCP-1 [12]. Using a rat $\mathrm{NO}_{2}$ exposure model, we recently demonstrated a reduced capacity of AM from exposed animals to produce superoxide radicals following in vitro stimulation with zymosan as phagocytic stimulus [13]. Moreover, AM from these animals showed a shift to an alternatively activated phenotype, mainly characterized by a reduced expression of the proinflammatory cytokines TNF- $\alpha$ and IL-1 $\beta$ and a significantly increased expression and production of the antiinflammatory cytokine IL-10 [14]. So far, it is not clear whether these changes are due to the appearance of a phenotypical different AM subpopulation or due to a functional shift in the already present AM population.

Therefore, the aim of the present study was to investigate whether phenotypically different AM subpopulations are present in the lung following $\mathrm{NO}_{2}$ exposure and whether these AM subpopulations show distinct functional properties. In fact we are able to show, that a phenotypically different AM subpopulation occurs in the lungs of $\mathrm{NO}_{2}$ exposed animals due to new infiltration. These cells show functional differences to already present AM with respect to mediator mRNA expression and production as well as mRNA expression for several matrix metalloproteinases.

\section{Materials and methods \\ Animal exposure}

Fischer344 rats were obtained from Charles River Wiga (Sulzfeld, Germany) at a body weight of about $120 \mathrm{~g}$ and C57BL/6 mice were purchased through Harlan Winkelmann (Borchen, Germany) at an age of $6-8$ weeks. The animals were housed in wire cages at room temperatures in a 12-12 hours light-dark cycle and given food and water ad libitum.

Groups of rats were continuously exposed to $10 \mathrm{ppm} \mathrm{NO}$ for 24 h, 3 and 20 days, control animals breathed normal air. Exposure regimes were designed that animals of all exposure groups could be analyzed simultaneously. Mice were exposed for 7 days. Exposure was carried out in airtight chambers having a total volume of $60 \mathrm{l}$ and equipped with in- and outlet for the gas mixture and a ventilator to ensure equal distribution of the gas atmosphere throughout the whole chamber. $\mathrm{NO}_{2}$ (MesserGriesheim, Duisburg, Germany) was adjusted to a final concentration of $10 \mathrm{ppm}$ by mixing with compressed air and directed through the chambers at a constant gas flow of $15 \mathrm{l} / \mathrm{min}$. $\mathrm{NO}_{2}$ concentration was controlled at least twice a day using a $\mathrm{NO}_{2}$-sensitive electrochemical element (ECS 102-1, MPSensor Systems, Munich, Germany). Exposures were performed at temperatures of $22 \pm 2{ }^{\circ} \mathrm{C}$ and a relative humidity of $50 \pm 5 \%$. Animal housing conditions and $\mathrm{NO}_{2}$ exposure met German and International Guidelines.

\section{Bronchoalveolar lavage}

Following anesthetization by intraperitoneal application of sodium pentobarbital (100 mg/kg body weight; Narcoren $^{\circledR}$, Merial GmbH, Hallbergmoos, Germany) mixed with 100 IU heparin (Liquemin ${ }^{\circledR}$, Roche, Mannheim, Germany) the tracheas were cannulated and the animals were thoracotomized. The lungs were perfused via the 
pulmonary artery with prewarmed $\left(37^{\circ} \mathrm{C}\right)$ perfusion buffer (PBS + $\mathrm{Ca}^{2+}, \mathrm{Mg}^{2+}$ supplemented with $10 \mathrm{mM}$ HEPES, $50 \mu \mathrm{g} / \mathrm{ml}$ gentamicin and $10 \mathrm{U} / \mathrm{ml}$ penicillin, $\mathrm{pH}$ 7.4) until they became white and hearts and lungs were removed en bloc. Finally, lungs were lavaged extracorporally 6 times with $8 \mathrm{ml}$ lavage buffer $\left(\mathrm{Ca}^{2+} / \mathrm{Mg}^{2+}\right.$-free PBS with $10 \mathrm{mM}$ Hepes, $0.2 \mathrm{mM}$ EGTA, $50 \mu \mathrm{g} / \mathrm{ml}$ gentamicin and $10 \mathrm{U} / \mathrm{ml}$ penicillin, $\mathrm{pH}$ 7.4) which was allowed to passively run out after each instillation while gentle massaging the lung. Bronchoalveolar lavage fluid was centrifuged at $300 \times \mathrm{g}$ for $10 \mathrm{~min}$ at $4{ }^{\circ} \mathrm{C}$ to obtain alveolar cells. Contaminating red blood cells were eliminated by hypotonic lysis for 30 seconds with double-distilled water. Remaining cells were washed twice in PBS.

\section{FACS analysis}

Surface marker expression of AM was investigated by labeling of the cells with several primary antibodies directed to rat myeloid cell epitopes (kindly provided by Dr. Steiniger, Institute of Anatomy, Philipps University of Marburg; see Table 2) combined with a signal amplification system to overcome draw-backs evoked by the high AM autofluorescence and subsequent flow cytometric analysis. Briefly, cells were suspended in FACS buffer (PBS supplemented with $1 \%$ fetal calf serum and $0.1 \%$ sodium azide) at a concentration of $2 \times 10^{6}$ cells $/ \mathrm{ml}$ and $250 \mu \mathrm{l}$ of the cell suspensions were labeled with $50 \mu \mathrm{l}$ of the appropriately diluted, unlabeled primary antibody. Bound antibodies were than detected by addition of a biotinylated goat antimouse antibody (Becton Dickinson - Pharmingen, Heidelberg, Germany) followed by phycoerythrin (PE)-conjugated streptavidin (Becton Dickinson - Pharmingen). This complex was then incubated with a biotinylated antistreptavidin antibody (Vector, Burlingame, CA) and, finally, all free biotin binding sites were labeled by repeated addition of PE-labeled streptavidin.

Mouse AM were labeled with anti-mouse CD11b-biotin and fluorescein isothiocyanate (FITC)-labeled strepatvidin as secondary reagent (both purchased from Becton Dickinson - Pharmingen) and the macrophage-specific antibody F4/80 conjugated to Alexa647 (Caltag, Hamburg, Germany).

All incubations were performed at $4{ }^{\circ} \mathrm{C}$ for 30 min and after each incubation, unbound reagents were washed out by three washing steps with FACS buffer. Stained cells were finally suspended in $250 \mu$ l FACS fixation buffer (FACS buffer plus $1 \%$ formaldehyde) and $250 \mu \mathrm{l}$ of azide free Diluid ${ }^{\circledast}$ (J.T. Baker B.V., Deventer, The Netherlands) were added prior to FACS analysis. Appropriate controls were performed to ensure the specificity of the labeling reactions including use of irrelevant isotype control immunoglobulins and omission of key reagents.
Flow cytometric analysis of stained cells was carried out using a FACScan (Becton Dickinson). A forward scatter life gate was set and 5,000 events were measured for each sample using FACScan Plus software. Data analysis was performed with the PC-compatible FlowMate software (Dako A/S, Glostrup, Denmark).

\section{Preparation of purified AM subpopulations by magnetic bead separation}

AM subpopulations were separated by a two-step purification protocol using the MACS magnetic cell sorting system (Miltenyi Biotec, Bergisch Gladbach, Germany). In the first step, neutrophils and T cells were removed to obtain purified total AM that were further separated in a second step in ED7- and ED7+ AM. Therefore, BAL cells were resuspended in $5 \mathrm{ml}$ MACS buffer (PBS without $\mathrm{Ca}^{2+} / \mathrm{Mg}^{2+}+2 \mathrm{mM}$ EDTA + 0.5\% bovine serum albumin) and subsequently filtered through $75 \mu \mathrm{m}$ and $30 \mu \mathrm{m}$ filters to remove cell clumps. After washing and resuspension in $5 \mathrm{ml}$ MACS buffer, $10 \mu \mathrm{l}$ of HIS-48-biotin (labels rat neutrophil granulocytes; Becton Dickinson - Pharmingen) antibody solution were added. Cell suspensions were incubated at $4{ }^{\circ} \mathrm{C}$ on a roller shaker for $20 \mathrm{~min}$ and washed twice in MACS buffer. Subsequently, cells were suspended in $80 \mu \mathrm{l}$ MACS buffer plus $10 \mu \mathrm{l}$ streptavidinbeads and $10 \mu \mathrm{l}$ rat pan T cell beads. After another $20 \mathrm{~min}$ of incubation, cells were washed, suspended in $0.5 \mathrm{ml}$ MACS buffer and applied to MACS-MS columns that were placed in an OctoMACS separation unit (all materials from Miltenyi). Subsequently, the columns were washed three times with $0.5 \mathrm{ml}$ MACS buffer. Cells in the pooled flow throughs represented purified total AM with a purity of $>99 \%$. Similar to the first step protocol, these cells were than labeled with the ED-7 antibody (Serotec, Duesseldorf, Germany) followed by anti-mouse-IgG beads (Miltenyi) and separated on MACS-MS columns. Cells in the flow throughs were collected as ED7- AM, and ED7+ AM were obtained by washing the columns after removal from the magnet. Finally, cells were washed and resuspended in the respective buffer or medium for subsequent applications.

\section{In vivo labeling of resident AM with PKH26}

Three days prior to the initiation of $\mathrm{NO}_{2}$ - or sham-exposure, $100 \mu \mathrm{l}$ of a $300 \mu \mathrm{M}$ solution of PKH26 dissolved in Diluent C (PKH26 Red Fluorescent Phagocytic Cell Linker Kit, Sigma, Deisenhofen, Germany) were intravenously injected into mice, resulting in an estimated serum concentration of $15 \mu \mathrm{M}$ according to Maus et al. [12].

\section{Quantitative reverse transcriptase polymerase chain reaction}

Total RNA from purified AMs was prepared using the RNeasy Total RNA Mini Kit (Qiagen, Hilden, Germany) according to manufacturer's protocol. For first-strand 
Table I: Primer sequences.

\begin{tabular}{|c|c|c|}
\hline Gene & Primer & Sequence \\
\hline \multirow[t]{2}{*}{ TNF- $\alpha$} & sense & 5'- TCC CAA ATG GGC TCC CTC TC -3' \\
\hline & antisense & 5'- AAA TGG CAA ACC GGC TGA CG -3' \\
\hline \multirow[t]{2}{*}{ IL-I0 } & sense & 5'- CCA TGG CCC AGA AAT CAA GG -3' \\
\hline & antisense & 5'- TCT TCA CCT GCT CCA CTG CC -3' \\
\hline \multirow[t]{2}{*}{ iNOS } & sense & 5'- TTG CCA CGG AAG AGA CGC AC -3' \\
\hline & antisense & 5'- CAG GCA CAC GCA ATG ATG GG -3' \\
\hline \multirow[t]{2}{*}{ IL-I 2 p 40} & sense & 5'- GTT CTT CGT CCG CAT CCA GC -3' \\
\hline & antisense & 5'- GCA TTG GAC TTC GGC AGA GG -3' \\
\hline \multirow[t]{2}{*}{ MMP-2 } & sense & 5'- AGT TCC CGT TCC GCT TCC AG -3' \\
\hline & antisense & 5'- CCA CAC CTT GCC ATC GCT TC -3' \\
\hline \multirow[t]{2}{*}{ MMP-7 } & sense & 5'- TGC CGG AGA CTG GAA AGC TG -3' \\
\hline & antisense & 5'- GGT GCA AAG GCA TGG CCT AG -3' \\
\hline \multirow[t]{2}{*}{ MMP-8 } & sense & 5'- TGC CCG ACT CTG GTG ATT TC -3' \\
\hline & antisense & 5'- GGG TTG ATG GCA CAC TCC AG -3' \\
\hline \multirow[t]{2}{*}{ MMP-9 } & sense & 5'- ACT TGC CGC GAG ACG TGA TC -3' \\
\hline & antisense & 5'- TTG CCG TCG AAG GGA TAC CC -3' \\
\hline \multirow[t]{2}{*}{ MMP-I2 } & sense & 5'- TCG ATG TGG AGT GCC TGA TG -3' \\
\hline & antisense & 5'- ATC CGC ACG CTT CAT GTC TG -3' \\
\hline \multirow[t]{2}{*}{ L32 } & sense & 5'- AAG CGA AAC TGG CGG AAA CC -3' \\
\hline & antisense & 5'- CTG GCG TTG GGA TTG GTG AC -3' \\
\hline
\end{tabular}

cDNA synthesis, RNA was treated with DNase I (Gibco Invitrogen, Groningen, The Netherlands) and subsequently reverse-transcribed using an oligo $(\mathrm{dT})_{20}$ primer (MWG Biotech, Ebersberg, Germany) and Omniscript Reverse Transcriptase (Qiagen). All procedures were carried out according to supplier's recommendations.

Primer sequences were generated from the respective mRNA sequences obtained from the European Molecular Biology Laboratory (EMBL) gene bank and primers were synthesized by MWG Biotech. Primer sequences are summarized in Table 1. Quantitative LightCycler PCR was performed by use of the QuantiTect ${ }^{\circledR}$ SYBR $^{\circledR}$ Green PCR Kit (Qiagen). Therefore, $12.5 \mu \mathrm{l}$ QuantiTect ${ }^{\circledR}$ SYBR $^{\circledR}$ Green Master Mix, $0.5 \mu$ l of each primer at a concentration of 50 $\mathrm{pmol} / \mu \mathrm{l}$ and $10.5 \mu \mathrm{l}$ water were added to $1 \mu \mathrm{l}$ of cDNA, standard or water (negative control). $20 \mu \mathrm{l}$ of each mix were transferred into LightCycler capillaries (Roche, Mannheim, Germany) that were subjected to the following temperature profile within the LightCycler equipment (Roche): initial $15 \mathrm{~min}$ at $95^{\circ} \mathrm{C}$ to activate the enzyme, and 55 cycles of $95^{\circ} \mathrm{C}(15 \mathrm{sec})-60^{\circ} \mathrm{C}(30 \mathrm{sec})-72^{\circ} \mathrm{C}$ (15 sec). Finally, product identity was verified by melting curve analysis. Calculation of crossing points was performed using the second derivative maximum method (included in LightCycler software) for the unknown samples and for DNA standards of known concentrations generated from purified PCR-products of the respective gene. Unknown sample concentrations were than calculated from the standard curve. Sample equality was confirmed by comparable expression of the housekeeping gene L32.

\section{In vitro stimulation of $B A L$ cells}

Separated ED7- and ED7+ AM were washed twice in $\mathrm{Ca}^{2+}$ $\mathrm{Mg}^{2+}$-free PBS and were suspended in RPMI 1640 (Linaris, Bettingen, Germany) supplemented with $2 \mathrm{mM} \mathrm{L}$ glutamine, $10 \mathrm{mM}$ HEPES, $1 \mathrm{mM}$ sodium pyruvate, $1 \times$ non-essential amino acids, $100 \mathrm{U} / \mathrm{ml}$ penicillin and 100 $\mu \mathrm{g} / \mathrm{ml}$ streptomycin (all purchased from Life Technologies, Gaithersburg, MD) and $1 \%$ fetal calf serum (FCS, Biochrom, Berlin, Germany). The number of living cells was determined using the CASY ${ }^{\circledR} 1$ Cell Counting System (Schärfe Systems, Reutlingen, Germany) and AMs were incubated at a final concentration of $1 \times 10^{6}$ cells $/ \mathrm{ml}$ in 48-well cell culture plates (Costar, Corning, NY) at a total volume of $250 \mu \mathrm{l}$. Cell cultures were performed in the absence or presence of LPS from E. coli O127:B8 (Difco Laboratories, Chicago, MI) at $37^{\circ} \mathrm{C}$ in a humid atmosphere containing $5 \% \mathrm{CO}_{2}$. Cells were allowed to adhere to the culture plate surface for about 1 hour before LPS (100 $\mathrm{ng} / \mathrm{ml}$ ) was added. Cell culture supernatants were collected after 24 hours of culture and stored until use for mediator quantitation at $-20^{\circ} \mathrm{C}$.

\section{Cytokine quantitation in cell culture supernatants}

Cell culture supernatant TNF- $\alpha$ and IL-10 were measured with rat specific enzyme-linked immunosorbent assays (ELISAs) using matched antibody pairs with monoclonal capture and biotinylated detection antibodies and recombinant cytokines (all purchased from Becton Dickinson Pharmingen) as standards. ELISAs were performed according to a recently described protocol [15] using peroxidase-labeled streptavidin (Roche, Heidelberg, Germany) and o-phenylendiamine (Sigma, Deisenhofen, Germany) as substrate.

IL-12 p70 was quantitated using a commercially available ELISA to rat IL-12 p70 obtained from Biosource (Nivelles, Belgium) that was carried out according to the instructions of the manufacturer.

\section{Results}

Phenotypical characterization of AM of $\mathrm{NO}_{2}$-exposed rats First we analyzed by flow cytometry the expression of several surface molecules on AM obtained from rats exposed to $\mathrm{NO}_{2}$ for different times. Since AM are known to exert a high degree of autofluorescence that often interferes with the detection of surface molecules by FACS analysis we developed an amplifying system to improve the signal to background (autofluorescence) ratio. For this method, cells were initially labeled with the respective unconjugated primary antibody (all generated in the mouse) that was then detected by a biotinylated secondary antibody (goat anti-mouse IgG) followed by streptavidin-PE. This complex was now incubated with an anti-streptavidin antibody also labeled with biotin and, finally, streptavidin-PE was added again to cover all free biotin binding 
Table 2: Overview of cell surface expression of several cell surface molecules on rat alveolar macrophages and detection of differential expression in $\mathrm{AM}$ from $\mathrm{NO}_{2}$-exposed rats in comparison to $\mathrm{AM}$ from untreated controls. Expression analysis was performed by flow cytometry following staining of cells with the respective primary antibody and a signal amplification system.

\begin{tabular}{|c|c|c|c|}
\hline Antibody & Antigen/Cell population & Expression & Differences \\
\hline IA29 & ICAM-I (CD54) & medium & medium \\
\hline 107 & mononuclear phagocytes (CD68 ?) & medium & medium \\
\hline 3.2.3. & NKR-PI (CDI6I) & weak & no \\
\hline $3 A \mid 2$ & PECAM-I (CD3I) & weak & no \\
\hline $5 F I 0$ & VCAM-I & no & \\
\hline ARTI 8 & IL-2 receptor & no & \\
\hline ART65 & IL-2 receptor & no & \\
\hline ED2 & macrophage subset (no monocytes) & no & \\
\hline ED3 & macrophage subset (no monocytes) & no & \\
\hline ED4 & macrophages & medium & no \\
\hline ED7 & macrophage subset (CDII/CDI8; CR3) & medium & strong \\
\hline ED8 & macrophage subset (CDII/CD I8; CR3) & medium & small \\
\hline ED9 & macrophage subset $\left(\mathrm{SIRP}_{\alpha}, \mathrm{CDI} \mathrm{72a}\right)$ & strong & medium \\
\hline KIM2R & mature tissue macrophages & no & \\
\hline MAR3 & macrophage subset & no & \\
\hline $0 \times 2$ & CD200 & no & \\
\hline $0 \times 26$ & transferrin receptor (CD7I) & no & \\
\hline $0 \times 3$ & MHC-II (I-A like) & weak & small \\
\hline $0 \times 4$ & MHC-II (I-A like) & weak & small \\
\hline Ox41 & macrophages, DCs, PMNs (SIRP) & no & \\
\hline $0 \times 50$ & hyaluronic acid receptor (CD44) & medium & small \\
\hline $0 \times 52$ & activated monocytes & & \\
\hline $0 \times 6$ & MHC-II (RTI.B; I-A) & weak & medium \\
\hline $0 \times 62$ & DC subpopulation & no & \\
\hline $0 \times 8$ & $\mathrm{CD}_{\alpha}$ & no & \\
\hline Ox85 & L-selectin (CD62L) & no & \\
\hline RM-I & monocytes/macrophages/DCs/PMNs & strong & small \\
\hline RM-4 & all macrophages (no monocytes) & medium & strong \\
\hline RMA & macrophage subset (I20 kDa antigen) & medium & medium \\
\hline RP-I & neutrophiles (intracellular) & no & \\
\hline RP-3 & neutrophiles (intracellular) & no & \\
\hline W3/13 & leukosialin (CD43) & no & \\
\hline WT/I & LFA-I (CDIIa) & weak & no \\
\hline
\end{tabular}

sites. The application of this method enabled us to demonstrate the expression of surface molecules on alveolar macrophages that were not to be detected with conventional staining methods.

Having this method available we characterized normal AM of the rat using a number of antibodies that have been described or assumed to react with cells of the myeloid hematopoetic lineage and could demonstrate the surface expression of different molecules on AM as summarized in Table 2. In addition, for certain markers we were able to detect differences in the expression level in AM obtained from $\mathrm{NO}_{2}$-exposed rats in comparison to those obtained from untreated control animals (see Table 2 and Figure 1). With exception of ED9, $\mathrm{AM}$ from $\mathrm{NO}_{2}$-exposed animals showed always a higher expression of the respective surface marker when compared to cells from controls. The most remarkable differences were demonstrated using the antibodies ED7, ED9, RM-4 and OX6. Staining with ED7 clearly revealed the increasing occurrence of a second AM subpopulation that was characterized by a higher ED7 antigen expression, perhaps themselves representing two populations with medium and high ED7 expression. In contrast, ED9 showed a strong staining of all AM from treated and untreated animals, however, a subpopulation showing a slightly lower ED9 expression was found the longer the animals had been exposed to $\mathrm{NO}_{2}$. An increased surface expression was also found for the marker RM-4 and for MHC-class-II molecules, as detected by the antibody OX-6, in AM from exposed rats (Figure 1).

The major disadvantage of the applied signal amplification method is that double staining of cells is not possible. To further characterize the observed AM subpopulations we, therefore, separated AM obtained from 3 days exposed animals that show a low expression of ED7 (further referred as ED7-) from those showing a 


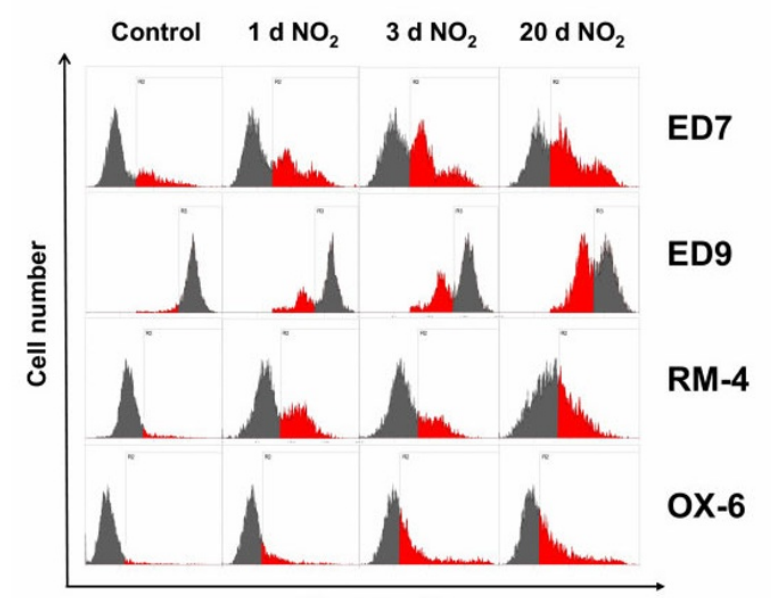

Fluorescence

\section{Figure I}

Flow cytometric analysis of AM from $\mathrm{NO}_{2}$-exposed and control rats. Rats were exposed to $\mathrm{NO}_{2}$ for the indicated times and BAL cells were stained with antibodies to ED7, ED9, RM-4, and OX-6. To overcome autofluorescence signals, primary antibodies were detected using a biotin-PE/streptavidinanti-streptavidin enhancing system and labeling of AM was analyzed by flow cytometry following gating by help of forward and sideward scatter properties. Shown are representative results of at least six animals per group.

high ED7 expression (ED7+) by use of magnetic bead separation after removing contaminating neutrophils and lymphocytes. As shown in the left panel of Figure 2 we obtained very pure AM subpopulations. These cells were now stained with the ED9 antibody combined with the described amplification system. Interestingly, we found that those AM showing a high level of ED7 expression are characterized by a reduced ED9 expression whereas the ED7- AM show the higher ED9 surface expression (Figure 2 , right panel). Thus, two AM subpoplations were demonstrated in the lungs of $\mathrm{NO}_{2}$-exposed rats that are characterized by the marker combinations ED7+/ED9low and ED7-/ ED ${ }^{\text {high, }}$ in the following still referred as ED7+ and ED7AM, respectively.

\section{Origin of $\mathrm{AM}$ subpopulations in $\mathrm{NO}_{2}$-exposed animals}

The occurrence of phenotypically different AM subpopulations may either be explained by a functional shift of already present AM or by the infiltration of macrophages that already represent the different phenotype. To address this question we applied the recently described method of in vivo labeling of resident AM by use of the fluorescent cell tracer PKH26 [12]. When intravenously applied in combination with a specific diluent, this dye is able to

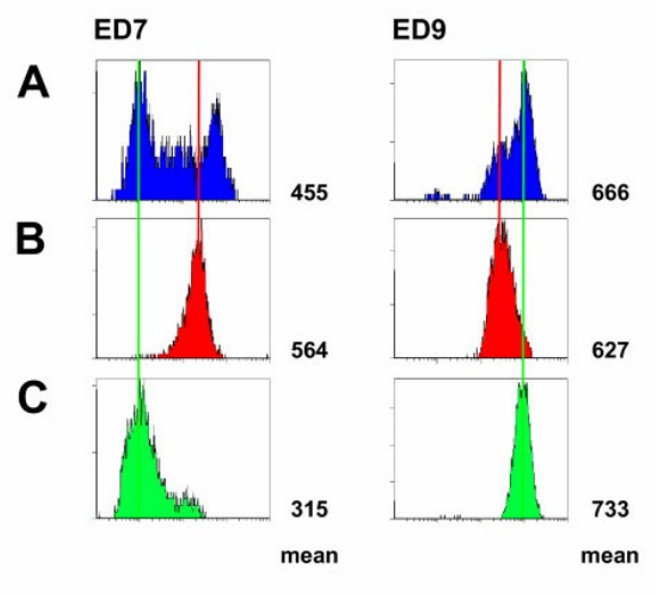

\section{Figure 2}

Flow cytometric analysis of ED7 and ED9 expression of AM following magnetic bead separation. AM of 3 days $\mathrm{NO}_{2}-$ exposed rats were separated due to their expression of the cell surface molecule ED7 using magnetic bead separation. Susbsequently, ED7 (left) and ED9 (right) expression was analyzed in unseparated AM (A), ED7-positive AM (B), and ED7-negative $A M(C)$. Numbers right of each histogram represent the mean fluorescence of the respective cell population. The figure clearly demonstrates that ED7-positive AM show a lower ED9 expression compared to ED7-negative AM. Shown is a representative data set of more than twenty animals.

label phagocytic cells within the organs, e.g. AM of the lungs, without a significant staining of blood monocytes. However, since this model is only applicable for the mouse, we switched to the mouse model for these investigations. Since we have recently shown that mice show a slower development of the inflammatory reaction towards $\mathrm{NO}_{2}[16]$, mice were exposed for 7 days for these analyses. Following this treatment, also in mice an AM subpopulation was observed that revealed an increased expression level of CD11b, the mouse homologue to ED7 (Fig. 3B). To analyze the origin of these cells, mice were treated with PKH26 three days prior to the onset of the $\mathrm{NO}_{2}$ - or sham-exposure. At this time point, almost $100 \%$ of the AM were positively stained whereas blood monocytes appeared PKH26-negative (data not shown). Whereas this situation did not change in the shamexposed control group, a significant portion of PKH26negative, newly recruited AM were observed in the lungs of $\mathrm{NO}_{2}$-exposed mice (Fig. 3C). A separate analysis of PKH26-positive and PKH26-negative cells revealed that the latter population was indeed characterized by a higher expression of the surface marker CD11b indicating that 


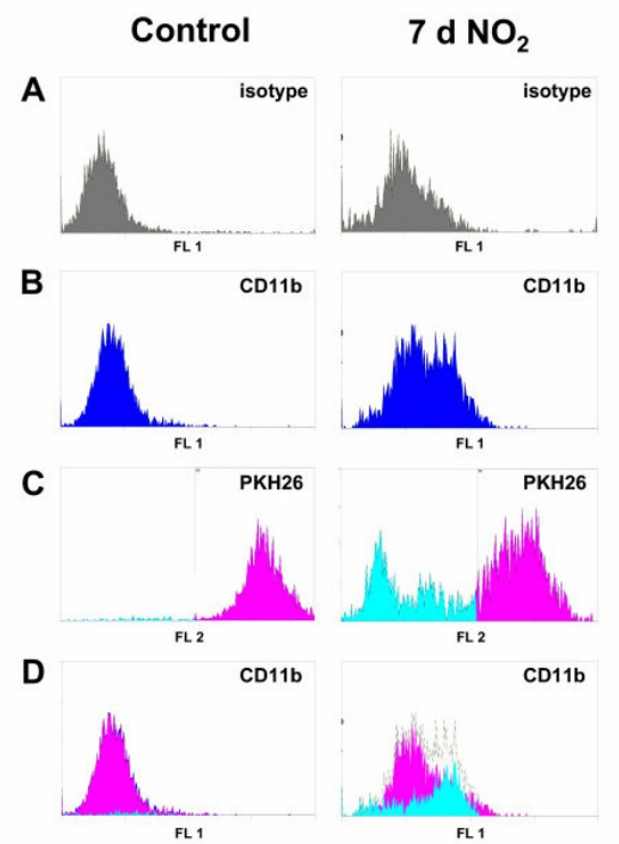

Figure 3

FACS analysis of CDI Ib and PKH26 labeling of AM from $\mathrm{NO}_{2}$-expsoed $\mathrm{C} 57 \mathrm{BL} / 6$ mice. Mice were intravenously given $\mathrm{PKH} 26$ in combination with diluent $\mathrm{C}$ three days prior to onset of a seven days $\mathrm{NO}_{2}$-exposure. Afterwards, AM were stained with F4/80-Alexa647 and CDI Ib-FITC. Isotype control (A), CDI Ib (B) and PKH26 (C) staining was subsequently analyzed by flow cytometry within the F4/80-positive cell population. (C) The proportion of $\mathrm{PKH} 26$-negative cells is shown in blue. Part (D) shows a separate analysis of CDI Ib-expression in PKH26-negative (blue histogram) and PKH26-positive AM (pink histogram) thereby clearly demonstrating that the CDI Ib-positive cell population mainly consists of PKH26-negative, newly recruited AM. Shown are representative results of eight animals per group.

the CD11b-positive AM subpopulation mainly originated from newly recruited macrophages (Figure 3D).

\section{Cytokine and iNOS mRNA expression in separated AM subpopulations}

For functional analysis of the two phenotypically different AM subpopulations we first compared the mRNA expression for several macrophage-derived mediators that are involved in the regulation of inflammatory responses. Therefore, ED7+ and ED7- AM of the rat were separated from the lungs of 3 days exposed animals. Total RNA was immediately isolated and following cDNA synthesis mediator mRNA expression was analyzed by quantitative PCR. As shown in Figure 4, no differences were observed between the two AM subpopulations in the expression of
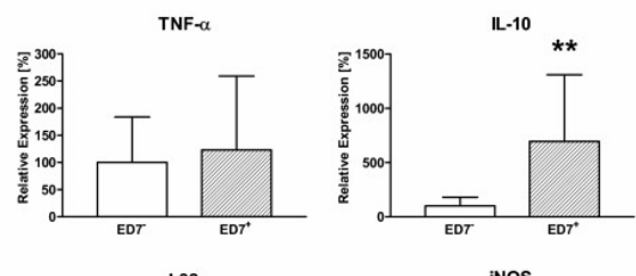

L32
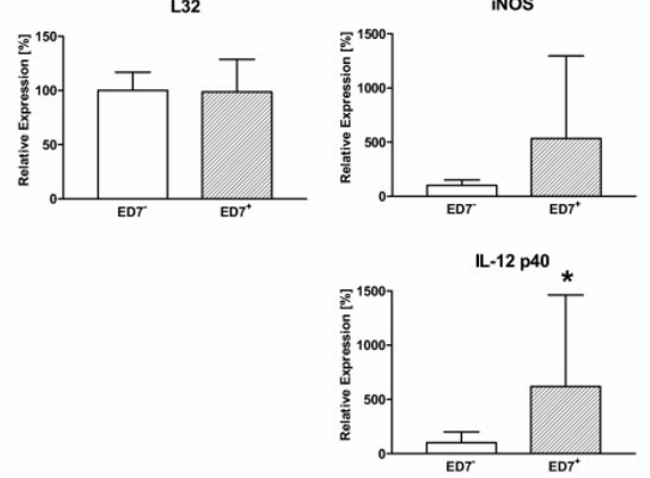

Figure 4

Cytokine and iNOS mRNA expression in AM subpopulations of $\mathrm{NO}_{2}$-exposed rats. ED7-positive and ED7-negative AM were separated from 3 days $\mathrm{NO}_{2}$-exposed rats and total RNA was prepared immediately after cell separation. Cytokine (TNF- $\alpha$, IL- I0, IL- I 2 p40) and iNOS mRNA expression was analyzed by quantitative RT-PCR with L32 as house-keeping gene control in ED7-negative (blank bars) and ED7-positive AM (hatched bars). Data are presented as relative expression with mean expression in ED7-negative AM was $100 \%$. Shown are mean \pm SD of six animals per group. Significance of differences was tested using the U-test according to Mann and Whitney and is indicated by $*$ for $\mathrm{p}<$ 0.05 or $* *$ for $\mathrm{p}<0.01$.

the proinflammatory cytokine TNF- $\alpha$. However, significantly increased mRNA levels were found in the ED7+ population for IL-12 p40 and iNOS. Interestingly, the expression of the antiinflammatory cytokine IL-10 was also higher in the ED7+ AM subpopulation (Fig. 4).

\section{Cytokine release by $A M$ subpopulations following in vitro stimulation}

To confirm the importance of the gene expression data we stimulated separated AM in vitro with $100 \mathrm{ng} / \mathrm{ml}$ LPS and analyzed the release of cytokines in the $24 \mathrm{~h}$ culture supernatants. When investigating proinflammatory cytokines we found that TNF- $\alpha$ was released at significantly higher amounts by AM of the ED7- subpopulation whereas IL-12 p70 was released at higher levels by the ED7+ subpopulation. However, the most important difference was observed for IL-10 that was detected in more than 100- 


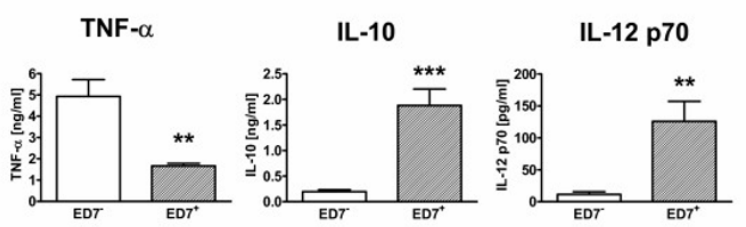

Figure 5

Differential cytokine production by LPS-stimulated AM subpopulations of $\mathrm{NO}_{2}$-exposed rats. ED7-positive and ED7negative $A M$ were separated from 3 days $\mathrm{NO}_{2}$-exposed rats and cultured in vitro for 24 hours in the presence of $100 \mu \mathrm{g}$ LPS. Subsequently, TNF- $\alpha$, IL-I0, and IL-I 2 p70 were quantitated in the culture supernatants of ED7-negative (blank bars) and ED7-positive AM (hatched bars) by ELISA. Data are presented as mean \pm SD of at least six animals per group. Significance of differences was tested using Students t-test and is indicated by $* *$ for $\mathrm{p}<0.01$ or $* * *$ for $\mathrm{p}<0.001$.

fold amounts in the supernatants of ED7+ AM when compared to the ED7- subpopulation (Fig. 5).

MMP mRNA expression in separated AM subpopulations In the context of an oxidant-induced inflammatory reaction in the lung AM are not only involved in the regulation of the inflammatory reaction by release of respective mediators but may also produce factors such as MMPs that may contribute to tissue remodelling and also lung damage under these conditions. We therefore investigated whether a specific subpopulation of AM is responsible for the expression of several metalloproteinases. The results of these analyses are summarized in Figure 6. With exception of MMP-2, that showed a comparable expression in both AM subpopulations, mRNA for all other tested MMPs (MMP-7, MMP-8, MMP-9, and MMP-12) were almost not detectable in the ED7- subpopulation but were found at significantly elevated levels in the ED7+ AM subpopulation.

\section{Discussion}

Exposure of rodents to $\mathrm{NO}_{2}$ have been shown to induce inflammatory reactions in the lung that have several features in common with the situation observed in patients that suffer from inflammatory lung diseases such as chronic obstructive lung disease (COPD). Due to it's poor water solubility $\mathrm{NO}_{2}$ may reach distal parts of the lung including small airways and lung parenchyma where it causes histopathological and functional changes. These alterations comprise histomorphological changes in lung parenchyma and vasculature $[17,18]$ with increased vascular permeability [14], loss of cilia in the airway epithelium [19], hypertrophy of bronchial epithelial cells [20], and mucus hypersecretion due to a hyperplasia of goblet cells. In addition, several changes in surfactant metabo-
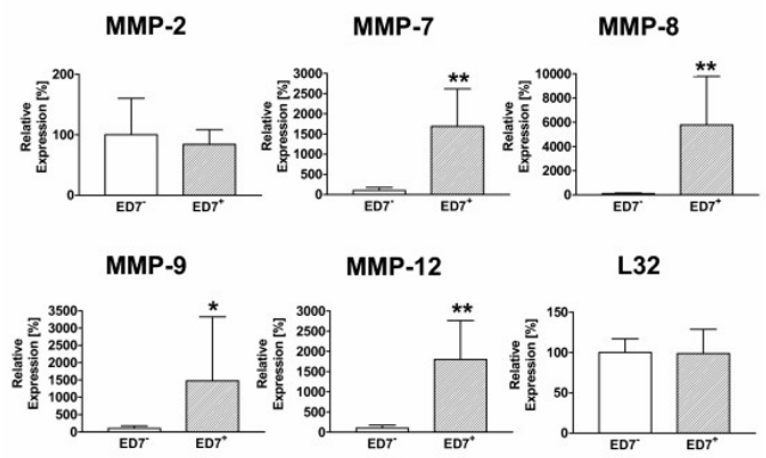

L32

Figure 6

mRNA expression for several MMPs in AM subpopulations of $\mathrm{NO}_{2}$-exposed rats. ED7-positive and ED7-negative AM were separated from 3 days $\mathrm{NO}_{2}$-exposed rats and total RNA was prepared immediately after cell separation. MMP-2, -7, -8, -9, and - 12 mRNA expression was analyzed by quantitative RTPCR with L32 as house-keeping gene control in ED7-negative (blankbars) and ED7-positive AM (hatched bars). Data are presented as relative expression with mean expression in ED7-negative AM was $100 \%$. Shown are mean \pm SD of six animals per group. Significance of differences was tested using the $U$-test according to Mann and Whitney and is indicated by $*$ for $p<0.05$ or $* *$ for $p<0.01$.

lism were described $[21,22]$ and a replacement of type-Ipneumocytes by type-II-cells was observed [20]. Moreover, prolonged exposure to $\mathrm{NO}_{2}$ may also cause changes in lung function such as limitation of airflow and increased expiration time that are indicative for the occurrence of airway obstruction [23] and may finally even lead to the development of emphysema $[24,25]$. Especially the last features are major characteristics of human COPD. As also observed in these patients, macrophages and neutrophil granulocytes are the most important inflammatory cell populations $[25,26]$. Using the identical $\mathrm{NO}_{2}$ exposure model as applied for the investigations described here we could recently demonstrate that neutrophils show an immediate infiltration and their number peaks in the BAL already at three days after onset of the exposure in rats [14]. Even though mice show a slower development of inflammatory changes [16], macrophages play the dominant role over the whole observation period in both species. With exception of day one in rats, significantly increased alveolar macrophage numbers have been observed over the whole observation period in rat and mice, thereby representing the major cell population at all time points [14]. However, only little is known about the role that AM play in the pathogenesis of chronic inflammatory lung diseases especially at early stages of their development. 
In the present study we could clearly demonstrate that a new phenotypically different AM subpopulation occurs in the lungs of rats and mice under the influence of oxidative/nitrosative stress exerted by exposure of the animals to $\mathrm{NO}_{2}$. Using $\mathrm{PKH}$ labeling of resident $\mathrm{AM}$ in mice we were able to show, that these macrophages represent newly recruited macrophages, a mechanism that is assumed to be similar in rats. These macrophages differ from already present AM by a higher expression of the surface marker ED7 (in rat) or its murine homologue CD11b. Interestingly, an increased expression of CD11b was also observed in AM from smokers [27]. In addition, other surface markers are also differentially expressed in AM from control and $\mathrm{NO}_{2}$-exposed animals, e.g. ED9, $\mathrm{RM}-4$ and MHC-class-II molecules, at least in the rat. AM are known to normally show a low expression of CD11b even though this molecule is a typical surface marker of cells of the monocyte/macrophage lineage in the blood and other tissues [28]. Thus, the limited CD11b expression seems to be a sign of tissue specific activation of AM that also show an elevated expression of the transcription factor PU.1 [29], a differential expression of protein kinase $\mathrm{C}$ isoforms [30] and a decreased DNA binding capacity of the transcription factor AP-1 [31] when compared to macrophages from other tissues. In addition, the proteome of AM differs significantly from that of blood monocytes [32]. Perhaps, AM-specific differentiation signals are underrepresented during an inflammatory process in the lung or these signals may not properly influence newly infiltrating macrophages under these circumstances. As a consequence, these alterations may lead to a different phenotype of AM that enter the lung during an inflammatory process in comparison to macrophages that infiltrate under non-pathological conditions. However, very recent data also suggest the existence of two phenotypically different monocyte populations that selectively enter healthy or inflamed tissue areas $[33,34]$. This would imply that the described AM subpopulations originated from already different monocyte subpopulations.

In the model presented here, newly recruited AM seem to have a dual role with respect to regulatory and effector functions. A major feature of these cells is their high expression and production of IL-10 which is in contrast to resident AM that do only poorly produce this cytokine even following LPS stimulation [35]. IL-10 is known to exert antiinflammatory properties [36] and, therefore, $\mathrm{ED}^{+} \mathrm{AM}$ seem to play a role in the control of the inflammatory reaction. On the other hand these $\mathrm{ED7}{ }^{+} \mathrm{AM}$ also produce higher amounts of IL-12, a cytokine that is involved in the activation of Thelper 1 (Th1) lymphocytes [37] that in turn may amplify a macrophage-dominated inflammatory reaction. The latter mechanism is supported by observations in CCR2 knock-out mice that lack the receptor for the CC-chemokine CCL2 (MCP-1; mono- cyte chemotactic protein-1). These animals show diminished inflammatory reactions due to an impaired migration of monocytes into inflammatory sites associated with decreased Th1 activities [38]. In line with these findings it has also been demonstrated that these mice exert enhanced Th2 responses [39,40]. In conclusion, our findings clearly suggest that the newly recruited ED7+AM are involved in the regulation of the ongoing inflammatory process. Whether the antiinflammatory effects of IL10 or the proinflammatory role of IL-12 (or even additional regulatory molecules) will dominate the regulatory function of ED7+ AM in our model has to be investigated in future studies.

In addition, $\mathrm{ED} 7+\mathrm{AM}$ are not only involved in regulatory processes but may also directly act as effector cells. With this respect the selective expression of several MMPs by these macrophages was a quite interesting finding. It is known that activated granulocytes and macrophages are major producers of these proteases [41], however, to our best knowledge this is the first description that a specific inflammatory macrophage subpopulation is almost selectively responsible for the production of certain MMPs, among them MMP-9 and MMP-12. Interestingly, lung macrophages from human smokers and COPD patients have also been reported to show an increased expression of MMP-9 [42] but macrophage subpopulations were not investigated. MMP-12 seems to play an important role in the development of emphysema at least in the mouse model since absence of this specific MMP inhibits the generation of cigarette-smoke induced emphysema in MMP12 knock out mice [43]. More recent investigations provide evidence that both, elastase activities, such as MMP12 , and collagenolytic activities, as exerted by MMP-2 and MMP-9, in combination lead to an effective destruction of lung parenchymal tissue that finally results in the generation of emphysema $[44,45]$. In addition, certain MMPs may also be involved in the regulation of inflammatory processes, e.g. by activation or inactivation of inflammatory mediators [46-48]. Thus, by expression of important $\mathrm{MMPs} E \mathrm{E} 7+\mathrm{AM}$ may contribute to the pathology of $\mathrm{NO}_{2}-$ induced lung damage and are further involved in the regulation of the inflammatory process.

\section{Conclusion}

Exposure of rodents to the oxidative/nitrosative agent $\mathrm{NO}_{2}$ leads to the infiltration of a new AM subpopulation that phenotypically and functionally differs from resident AM. There is no doubt that these AM by release of regulatory mediators and expression of MMPs strongly influence the mechanisms that regulate the inflammatory response to the inducing agent and are directly involved in the pathologic processes induced by $\mathrm{NO}_{2}$. Since $\mathrm{NO}_{2}$ and related molecules are major components of tobacco smoke it is likely that similar processes may occur in 
smokers and even patients suffering from COPD. Indeed, phenotypically and functionally different macrophages have been observed in sputum of those patients [49]. These macrophages represent a different compartment of the lung, however, their occurrence implicates that similar processes as described in our animal model may also occur in humans following oxidative/nitrosative stress. If so, these newly recruited macrophages may represent an interesting target for therapeutic approaches for the treatment of chronic inflammatory diseases of the lung.

\section{Competing interests}

The author(s) declare that they have no competing interests.

\section{Authors' contributions}

HG conceived of and designed the study, was involved in animal exposure and cell preparation, performed FACS analysis and drafted the manuscript.

AS was involved in animal exposure and cell preparation, carried out MACS separation of AM subpopulations and performed in vitro cell stimulation and mediator analysis.

SS was responsible for animal preparation, performed mRNA expression analyses, and helped in FACS and MACS procedures.

AW performed the PKH26 experiments and was involved in subsequent FACS analyses. In addition she helped carrying out mRNA-expression analyses.

HR helped in study design and coordination as well as in preparation of the manuscript.

DG participated in the design of the experiments, its coordination and manuscript preparation.

\section{Acknowledgements}

The study was funded by the German Ministry of Education and Research Grant No. 0IGC0I03.

\section{References}

I. Crapo JD, Harmsen AG, Sherman MP, Musson RA: Pulmonary immunobiology and inflammation in pulmonary diseases. Am J Respir Crit Care Med 2000, I 62:1983-1986.

2. Nicod LP: Pulmonary defense mechanisms. Respiration 1999 , 66:2-II.

3. Shapiro SD: The macrophage in chronic obstructive pulmonary disease. Am J Resp Crit Care Med 1999, I 60:S29-S32.

4. Lohmann-Matthes ML, Steinmüller C, Franke-Ullmann G: Pulmonary macrophages. Eur Respir J 1994, 7:1678-I689.

5. Lavnikova N, Prokhorova S, Helyar L, Laskin DL: Isolation and partial characterization of subpopulations of alveolar macrophages, granulocytes, and highly enriched interstitial macrophages from rat lung. Am J Respir Cell Mol Biol 1993, 8:384-392.

6. Laskin DL, Weinberger B, Laskin JD: Functional heterogeneity in liver and lung macrophages. J Leukoc Biol 200I, 70:I63-I70.
7. Dorger M, Munzing S, Allmeling AM, Messmer K, Krombach F: Phenotypic and functional differences between rat alveolar, pleural, and peritoneal macrophages. Exp Lung Res 200I, 27:65-76.

8. Ferrari-Lacraz S, Nicod LP, Chicheportiche R, Welgus HG, Dayer JM: Human lung tissue macrophages, but not alveolar macrophages, express matrix metalloproteinases after direct contact with activated T lymphocytes. Am J Respir Cell Mol Biol 200I, 24:442-45I.

9. Chelen CJ, Fang Y, Freeman GJ, Secrist H, Marshall JD, Hwang PT, Frankel LR, DeKruyff RH, Umetsu DT: Human alveolar macrophages present antigen ineffectively due to defective expression of B7 costimulatory cell surface molecules. J Clin Invest 1995, 95: I4I5-I42I.

10. Knapp S, Leemans JC, Florquin S, Branger J, Maris NA, Pater J, van Rooijen N, van der PT: Alveolar macrophages have a protective antiinflammatory role during murine pneumococcal pneumonia. Am J Respir Crit Care Med 2003, I67:17I-179.

II. Strickland D, Kees UR, Holt PG: Regulation of T-cell activation in the lung: aveolar macrophages induce reversible T-cell anergy in vitro associated with inhibition of interleukin-2 receptor signal transduction. Immunology 1996, 87:250-258.

12. Maus U, Herold S, Muth H, Maus R, Ermert L, Ermert M, Weissmann N, Rosseau S, Seeger W, Grimminger F, et al.: Monocytes recruited into the alveolar air space of mice show a monocytic phenotype but upregulate CDI 4. Am J Physiol Lung Cell Mol Physiol 200I, 280:L58-L68.

13. Olker C, Siese A, Stumpf S, Muller B, Gemsa D, Garn H: Impaired superoxide radical production by bronchoalveolar lavage cells from NO(2)-exposed rats. Free Radic Biol Med 2004, 37:977-987.

14. Garn H, Siese A, Stumpf S, Barth PJ, Müller B, Gemsa D: Shift towards an alternatively activated macrophage response in lungs of $\mathbf{N O}_{2}$-exposed rats. Am J Respir Cell Mol Biol 2003, 28:386-396.

I5. Garn H, Friedetzky A, Kirchner A, Jäger R, Gemsa D: Experimental silicosis: A shift to a preferential IFN- $\gamma$-based Th I response in thoracic lymph nodes. Am J Physiol Lung Cell Mol Physiol 2000, 278:LI22I-LI230.

16. Wegmann M, Fehrenbach A, Heimann S, Fehrenbach H, Renz H, Garn $H$, Herz U: NO2-induced airway inflammation is associated with progressive airflow limitation and development of emphysema-like lesions in C57BL/6 mice. Exp Toxicol Pathol 2005, 56:34I-350.

17. Barth PJ, Uhlarik S, Bittinger A, Wagner U, Ruschoff J: Diffuse alveolar damage in the rat lung after short and long term exposure to nitrogen dioxide. Pathol Res Pract 1994, 190:33-41.

18. Barth PJ, Müller B, Wagner U, Bittinger A: Quantitative analysis of parenchymal and vascular alterations in $\mathrm{NO}_{2}$-induced lung injury in rats. Eur Respir J 1995, 8: I I I I- II2I.

19. Chitano P, Rado V, Di Stefano A, Papi A, Boniotti A, Zancuoghi G, Boschetto P, Romano M, Salmona M, Ciaccia A, et al.: Effect of subchronic in vivo exposure to nitrogen dioxide on lung tissue inflammation, airway microvascular leakage, and in vitro bronchial muscle responsiveness in rats. Occup Environ Med 1996, 53:379-386.

20. Rombout PJ, Dormans JA, Marra M, van Esch GJ: Influence of exposure regimen on nitrogen dioxide-induced morphological changes in the rat lung. Environ Res 1986, 41:466-480.

21. Müller B, Barth PJ, Wichert Pv: Structural and functional impairment of surfactant protein $A$ after exposure to nitrogen dioxide in rats. Am J Physiol 1992, 263:LI77-LI84.

22. Müller B, Schäfer H, Barth PJ, Wichert Pv: Lung surfactant components in bronchoalveolar lavage after inhalation of $\mathrm{NO}_{2}$ as markers of altered surfactant metabolism. Lung 1994, 172:6I-72.

23. Wegmann M, Renz $H$, Herz U: Long-term NO2 exposure induces pulmonary inflammation and progressive development of airflow obstruction in C57BL/6 mice: a mouse model for chronic obstructive pulmonary disease? Pathobiology 2002, 70:284-286.

24. Blank J, Glasgow JE, Pietra GG, Burdette L, Weinbaum G: Nitrogendioxide-induced emphysema in rats. Lack of worsening by beta- aminopropionitrile treatment. Am Rev Respir Dis 1988, 137:376-379. 
25. Glasgow JE, Pietra GG, Abrams WR, Blank J, Oppenheim DM, Weinbaum G: Neutrophil recruitment and degranulation during induction of emphysema in the rat by nitrogen dioxide. Am Rev Respir Dis 1987, I35: I I29- I I36.

26. Pagani P, Romano M, Erroi A, Ferro M, Salmona M: Biochemical effects of acute and subacute nitrogen dioxide exposure in rat lung and bronchoalveolar fluid. Arch Environ Contam Toxicol 1994, 27:426-430.

27. Schaberg T, Lauer C, Lode H, Fischer J, Haller H: Increased number of alveolar macrophages expressing adhesion molecules of the leukocyte adhesion molecule family in smoking subjects. Association with cell-binding ability and superoxide anion production. Am Rev Respir Dis 1992, I46:I287-I293.

28. Gordon S: Pattern recognition receptors: doubling up for the innate immune response. Cell 2002, I I I:927-930.

29. Shibata Y, Berclaz PY, Chroneos ZC, Yoshida M, Whitsett JA, Trapnell BC: GM-CSF regulates alveolar macrophage differentiation and innate immunity in the lung through PU.I. Immunity 200I, I 5:557-567.

30. Monick MM, Carter AB, Gudmundsson G, Geist LI, Hunninghake GW: Changes in PKC isoforms in human alveolar macrophages compared with blood monocytes. Am J Physiol 1998, 275:L389-L397.

31. Monick MM, Carter AB, Hunninghake GW: Human alveolar macrophages are markedly deficient in REF-I and AP-I DNA binding activity. J Biol Chem I999, 274: |8075-I8080.

32. Jin M, Opalek JM, Marsh CB, Wu HM: Proteome comparison of alveolar macrophages with monocytes reveals distinct protein characteristics. Am J Respir Cell Mol Biol 2004, 3 I:322-329.

33. Geissmann F, Jung S, Littman DR: Blood monocytes consist of two principal subsets with distinct migratory properties. Immunity 2003, 1 9:71-82.

34. Sunderkotter C, Nikolic T, Dillon MJ, Van Rooijen N, Stehling M, Drevets DA, Leenen PJ: Subpopulations of mouse blood monocytes differ in maturation stage and inflammatory response. J Immunol 2004, I 72:4410-44I7.

35. Salez L, Singer M, Balloy V, Creminon C, Chignard M: Lack of IL-I 0 synthesis by murine alveolar macrophages upon lipopolysaccharide exposure. Comparison with peritoneal macrophages. J Leukoc Biol 2000, 67:545-552.

36. Mosmann TR: Properties and function of IL-I 0. Adv Immunol 1994, 56: I-26.

37. Brombacher F, Kastelein RA, Alber G: Novel IL-I 2 family members shed light on the orchestration of ThI responses. Trends Immunol 2003, 24:207-2I 2.

38. Boring L, Gosling J, Chensue SW, Kunkel SL, Farese RV Jr, Broxmeyer $\mathrm{HE}$, Charo IF: Impaired monocyte migration and reduced type I (ThI) cytokine responses in C-C chemokine receptor 2 knockout mice. J Clin Invest 1997, 100:2552-256I.

39. Blease K, Mehrad B, Standiford TJ, Lukacs NW, Gosling J, Boring L, Charo IF, Kunkel SL, Hogaboam CM: Enhanced pulmonary allergic responses to Aspergillus in CCR2-/- mice. J Immunol 2000, | 65:2603-26II.

40. Kim Y, Sung S, Kuziel WA, Feldman S, Fu SM, Rose CE Jr: Enhanced airway Th2 response after allergen challenge in mice deficient in CC chemokine receptor-2 (CCR2). J Immunol 200I, I 66:5183-5192.

41. Parks WC, Shapiro SD: Matrix metalloproteinases in lung biology. Respir Res 200I, 2:10-19.

42. Finlay GA, O'Driscoll LR, Russell KJ, D'Arcy EM, Masterson JB, FitzGerald MX, O'Connor CM: Matrix metalloproteinase expression and production by alveolar macrophages in emphysema. Am J Respir Crit Care Med I 997, I 56:240-247.

43. Hautamaki RD, Kobayashi DK, Senior RM, Shapiro SD: Requirement for macrophage elastase for cigarette smoke-induced emphysema in mice. Science 1997, 277:2002-2004.

44. Karkmann U, Radbruch A, Holzel V, Scheffold A: Enzymatic signal amplification for sensitive detection of intracellular antigens by flow cytometry. J Immunol Methods 1999, 230:1 I3-120.

45. Lanone S, Zheng T, Zhu Z, Liu W, Lee CG, Ma B, Chen Q, Homer RJ, Wang J, Rabach LA, et al.: Overlapping and enzyme-specific contributions of matrix metalloproteinases-9 and - I 2 in IL-I3induced inflammation and remodeling. J Clin Invest 2002, I | 0:463-474.

46. Haro H, Crawford HC, Fingleton B, Shinomiya K, Spengler DM, Matrisian LM: Matrix metalloproteinase-7-dependent release of tumor necrosis factor- alpha in a model of herniated disc resorption. J Clin Invest 2000, I05: I43-I50.

47. Yu Q, Stamenkovic I: Cell surface-localized matrix metalloproteinase-9 proteolytically activates TGF-beta and promotes tumor invasion and angiogenesis. Genes Dev 2000, 14: I63-176.

48. Schonbeck U, Mach F, Libby P: Generation of biologically active IL-I beta by matrix metalloproteinases: a novel caspase- Iindependent pathway of IL-I beta processing. J Immunol I998, | 6 | :3340-3346.

49. Frankenberger M, Menzel M, Betz R, Kassner G, Weber N, Kohlhaufl $M$, Haussinger K, Ziegler-Heitbrock L: Characterization of a population of small macrophages in induced sputum of patients with chronic obstructive pulmonary disease and healthy volunteers. Clin Exp Immunol 2004, I 38:507-5 I6.
Publish with Bio Med Central and every scientist can read your work free of charge

"BioMed Central will be the most significant development for disseminating the results of biomedical research in our lifetime."

Sir Paul Nurse, Cancer Research UK

Your research papers will be:

- available free of charge to the entire biomedical community

- peer reviewed and published immediately upon acceptance

- cited in PubMed and archived on PubMed Central

- yours - you keep the copyright

Submit your manuscript here:

http://www.biomedcentral.com/info/publishing_adv.asp
BioMedcentral 